\title{
Peritoneal Tuberculosis in a Patient with Chronic Myeloid Leukemia and Diabetes Mellitus: A Diagnostic Dilemma
}

\author{
BHUIAN TM ${ }^{\mathrm{a}}$, RAHMAN MM ${ }^{\mathrm{b}}$, HOQUE MN $^{\mathrm{c}}$, RAHIM MA ${ }^{\mathrm{d}}$, RAHMAN MM ${ }^{\mathrm{e}}$, RAHMAN MA $^{\mathrm{f}}$
}

\begin{abstract}
Tuberculosis (TB) may complicate patients with chronic myeloid leukaemia (CML) receiving imatinib mesylate, but concomitant diagnosis of $T B$ and $C M L$ is rare. Here, we present a middle aged Bangladeshi diabetic lady who got admitted because of prolonged pyrexia, ascites and splenomegaly. Diagnostic workup confirmed peritoneal TB
\end{abstract}

\section{Introduction}

Tuberculosis (TB) remains a major problem throughout the world. The prevalence is more in developing countries and the incidence is increasing in developed countries due to increased prevalence of human immunodeficiency virus (HIV) infection. It is estimated that one third of the world population is infected with Mycobacterium tuberculosis and nearly 3 million deaths occur each year due to TB. ${ }^{1}$ Pulmonary tuberculosis (PTB) is the commonest form, but it can affect other organs of the body.

Abdomen is one of the most common extra-pulmonary sites for TB. Abdominal TB accounts for 1 to $3 \%$ of total TB deaths. ${ }^{2}$ It has diverse presentations including gradual abdominal swelling, abdominal pain, chronic diarrhea, alteration of bowel habit, weight loss etc.

In immune suppressed patients, TB may be disseminated to involve more than two organ systems. Large number of TB cases occur in patients undergone allogenic bone marrow transplantation, patients receiving prolonged

1. Dr. Tareq Mahmud Bhuian, FCPS (Medicine), Associate Professor \& Head, Dept of GHPD, BIRDEM.

2. Dr. Md. Mahbubur Rahman, MD (Gastroenterology), SMO, Dept of GHPD, BIRDEM.

3. Dr. Md. Nazmul Hoque, MD (Gastroenterology), Junior Consultant, Dept of GHPD, BIRDEM.

4. Dr. Muhammad Abdur Rahim, FCPS (Medicine), Registrar, Dept of Medicine, BIRDEM.

5. Dr. Md. Motiur Rahman, MBBS, SMO, Dept of GHPD, BIRDEM.

6. Dr. Md. Anisur Rahman, FCPS (Medicine), Professor, Dept of GHPD, BIRDEM.

Address of Correspondence: Muhammad Abdur Rahim, FCPS (Medicine), Registrar, Dept of Medicine, BIRDEM. E-mail: muradrahim23@yahoo.com.

Received: 14 August, 2012

Accepted: 09 July, 2013 and CML. Being an uncommon entity, we are reporting the case.

Key words: abdominal tuberculosis, chronic myeloid leukaemia, disseminated tuberculosis, haematological malignancy.

(Birdem Med J 2013; 3(2): 113-115)

corticosteroid or infliximab therapy for rheumatological diseases and patients receiving imatinib mesylate for chronic myeloid leukaemia (CML). ${ }^{3-7} \mathrm{~TB}$ can complicate acute leukaemias and lymphomas, but concomitant diagnosis of TB and CML is an uncommon entity. ${ }^{8-14}$

\section{Case report}

A 52-year-old diabetic lady presented with one month history of low grade, intermittent fever and gradual abdominal distension for two weeks. She did not have any cough, haemoptysis, night sweats, jaundice, leg swelling, chest pain, palpitation, joint pain or weight loss. She was afebrile, mildly anaemic and haemodynamically stable. There was no jaundice or lymphadenopathy. Abdominal examination revealed hepatosplenomegaly with ascites. Examination of chest and precordium revealed normal findings. There was no signs of meningeal irritation.

Her hemoglobin $(\mathrm{Hb})$ was $10.4 \mathrm{gm} / \mathrm{dl}$, total WBC count $22,500 / \mathrm{cmm}$ with normal differentials, platelet count $5,36,000 / \mathrm{cmm}$, ESR $30 \mathrm{~mm}$ in $1^{\text {st }}$ hour. PBF revealed nonspecific morphology with mildly left shifted neutrophilic leucocytosis and thrombocytosis. Urine $\mathrm{RE}$ was normal. Urine $\mathrm{C} / \mathrm{S}$ and blood $\mathrm{C} / \mathrm{S}$ showed no growth. Abdominal USG revealed fatty liver (Grade II), marked ascites and splenomegaly. Chest X-ray PA view was normal. MT was negative. Liver and renal biochemistry were normal. Serum uric acid level was raised, $13.7 \mathrm{mg} / \mathrm{dl}$. Fasting blood glucose was $7.1 \mathrm{mmol} /$ $\mathrm{L}, \mathrm{HbAlc}$ was $8.2 \%$. Straw coloured ascitic fluid had increased total WBC count with predominant lymphocytes (total WBC 3,500 cell/cmm, polymorph $20 \%$, lymphocyte $80 \%$ ), RBC $800 \mathrm{cell} / \mathrm{cmm}$, total protein $60.0 \mathrm{gm} / \mathrm{L}$, albumin $32.0 \mathrm{gm} / \mathrm{L}$. No malignant cells or AFB 
was found in ascitic fluid. Adenosine deaminase (ADA) and CA 125 were $65.6 \mathrm{U} / \mathrm{L}$ and $>500 \mathrm{U} / \mathrm{L}$ respectively. SAAG was $6.0 \mathrm{gm} / \mathrm{L}$ (low gradient). Viral markers for hepatitis B and C were negative. Prothombin time and upper GI endoscopy were normal.

Bone marrow examination was suggestive of myeloproliferative disorder but possibility of a secondary reactive condition could not be ruled out. Diagnostic laparoscopy showed moderate amount of straw color ascitic fluid. Numerous seedlings were seen involving the whole parietal and visceral peritoneum and in omentum. Histopathological examination of peritoneal biopsy showed multiple epitheloid cell granuloma, some multinucleated giant cells and chronic inflammatory cellular infiltrate suggestive of granulomatous inflammation histologically consistent with tuberculosis (Figure 1). So, the patient was diagnosed as a case of peritoneal TB with leukamoid reaction with DM. Treatment with standard anti-TB drugs was started.

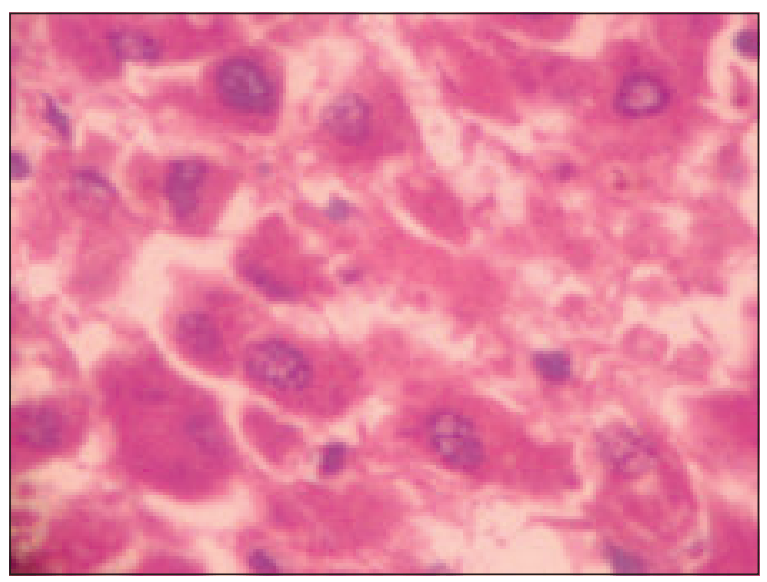

Fig.- 1: Peritoneal biopsy showing granuloma

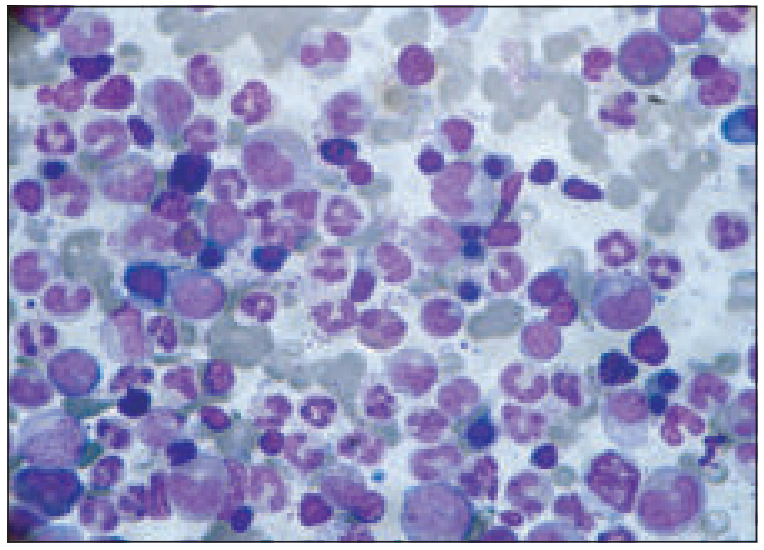

Fig.-2: $P B F$ suggestive of $C M L$

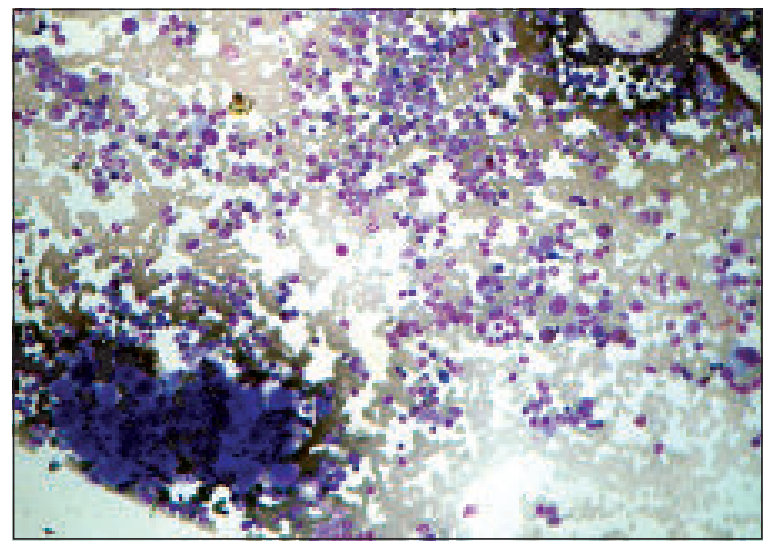

Fig-.3: Bone marrow showing features of CML

On follow up visit after 2 weeks a totally different picture was observed (Hb- $7.7 \mathrm{gm} / \mathrm{dl}$, total WBC count- 55,000/ cmm with $10 \%$ myelocytes, platelet count- $7,75,000 / \mathrm{cmm}$, ESR- $83 \mathrm{~mm}$ in $1^{\text {st }}$ hour). PBF was suggestive of CML (Figure 2). Repeat bone marrow examination showed active and normoblastic erythropoisis, grossly hyperactive granulopoisis and left shift with predominant myelocytes and segmented forms and increased megakaryocytes; findings were suggestive of CML (Figure 3). BCR-ABL gene rearrangement done by real time PCR was $79.08 \%$ which was highly significant.

Treatment with imatinib mesylate was started along with continuation of anti-TB drugs.

After six weeks she was clinically well, and her haematological parameters improved (Hb-10.8 gm/dl, total WBC-13,200/cmm, platelet count $4,06,000 / \mathrm{cmm}$, ESR- $35 \mathrm{~mm}$ in $1^{\text {st }}$ hour).

\section{Discussion}

Infection is the leading cause of morbidity and mortality in patients with hematological malignancies. Viral infections, Gram negative septicemia, systemic fungal infections and tuberculosis can occur. The prevalence of TB in patients with hematological malignancies is $1.8-2.2 \%{ }^{8,15} \mathrm{~TB}$ occurs $2-9$ times more in patients with hematological malignancies as compared with the general population. ${ }^{8} 16$ In such patients, extra-pulmonary involvement and atypical clinical manifestations are common. ${ }^{17,18}$ Extra-pulmonary TB ranges from $16 \%$ to $78 \%$ for all kinds of TB disease in patients with haematological malignancies. ${ }^{18,19}$ 
In literature review, a number of cases had been described in whom imatinib treatment for CML was complicated by activation of latent TB. ${ }^{7}$ But without such a treatment, occurrence of TB in patient with CML is an uncommon entity and rare cases were reported. ${ }^{12-}$ ${ }^{14}$ Silva et al. in a large retrospective study found only one case of TB among $45 \mathrm{CML}$ cases. ${ }^{11}$ In our patient, peritoneal TB was diagnosed first and haematological parameters initially gave us an impression of leukamoid reaction, but the initial bone marrow examination failed to identify any granuloma, AFB or malignancy and subsequently, within the next two weeks the typical picture of CML became obvious.

The diagnosis of extra-pulmonary tuberculosis could be delayed because of atypical presentations, lack of tissue proof and cultures. In our case, diagnostic laparoscopy and peritoneal biopsy could promptly and efficiently confirm the diagnosis of TB. So, in patients with prolonged fever without definite etiology, tuberculosis should be one of the differential diagnoses in clinical practice.

As soon as the TB diagnosis is established, standard anti-TB drugs should be initiated. It is recommended that, dose of imatinib mesylate should be increased by $50 \%$ in diagnosed CML cases when rifampicin is added. ${ }^{20}$ In our case, we are treating the patient with anti-TB drugs and imatinib $600 \mathrm{mg} /$ day. She is improving satisfactorily and we are keenly observing her for any possible drug related adverse effect.

\section{Conclusion}

Though uncommon, yet it is not impossible to have concomitant TB and CML. Clinicians should consider TB in the differential diagnoses of prolonged fever in patients with hematological malignancies, particularly in regions of high endemicity.

\section{References}

1. Limon HB. Infections due to Mycobacteria. In: Dale DC (ed). Scientific American Medicine. University of Washington Medical Center; Seattle 1995:1-25.

2. Uzunkoy A, Harma M, Harma M. Diagnosis of abdominal tuberculosis: Experience from 11 cases and review of the literature. World J Gastroenterol 2004;10(24):3647-49.

3. Kindler T, Schindel C, Brass U, Fischer T. Fatal sepsis due to mycobacterium tuberculosis after alogenic bone marrow transplantation. Bone Marrow Transplant 2001; 27: 21718.
4. Campos A, Vaz CP, CampilhoF, MoraisA, Guimarães MA, Lopes $\mathrm{C}$, et al. Central nervous system (CNS) tuberculosis following allogeneic stem cell transplantation. Bone Marrow Transplantation 2000;25(5):567-69.

5. Sahn SA, Lakshminarayan S. Tuberculosis after corticisteroid therapy. Br J Dis Chest 1976; 70: 195-205.

6. Broussais F, Kawashima M, Marotte H, Miossec P. Chronic myeloid leukaemia and toberculosis in a patient with rheumatoloid arthritis treated with infliximab. Ann Rheum Dis 2005;64:509-10.

7. Daniels JM, Vonk-Noordegraff A, Janssen JJ, Postmas PE, Altena RV. Tuberculosis complicating imatinib treatment for chronic myeloid leukaemia. EurRespir J 2009; 33 (3): 670-72.

8. Chen CY, ShengWH, Cheng A, Tsay W, Huang SY, Tang $\mathrm{JL}$, et al. Clinical characteristics and outcomes of Mycobacterium tuberculosis disease in adult patients with hematological malignancies. BMC Infectious Diseases 2011; 11: 324 .

9. Mishra P, Kumar R, Mahapatra M, Sharma S, Dixit A, Chaterjee T, et al. Tuberculosis in acute leukemia: a clinicohematological profile. Hematology 2006; 11: 335-40.

10. Stefan DC, Kruis AL, Schaaf HS, Wessels G. Tuberculosis in oncology patients. Ann Trop Paediatr 2008; 28:111-16.

11. Silva FA, Matos JO, de Q Mello FC, Nucci M. Risk factors for and attributable mortality from tuberculosis in patients with hematological malignancies. Haematologica 2005; 90: 1110-15.

12. Panikar N, Sikka M, Singh N. Concurrent chronic myelogenous leukaemia and tuberculous lymphadenitis. Acta Cytol 2005; 49(6): 650-52.

13. Shohet SB, Blum SF. Coincident basophilic chronic myelogenous leukaemia and pulmonary tuberculosis associated with extreme elevations of blood histamine levels and maturity onset asthma. Cancer 1968; 22(1):173-74.

14. Andre J, Schwartz R, Dameshek W. Tuberculosis and Myelosclerosis with Myeloid Metaplasia: Report of Three Cases. JAMA 1961;178(13):1169-74.

15. Siddiqui MA, Abdullah AK, Quraishy MU, Tajuddin M. Pulmonary tuberculosis and leukaemia. Ind J Tub 1977; 24 (1): 34-36.

16. Libshitz HI, Pannu HK, Elting LS, Cooksley CD. Tuberculosis in cancer patients: an update. J Thorac Imaging 1997; 12: 41-46.

17. Maartens G, Wilkinson RJ. Tuberculosis. Lancet 2007; 370: 2030-43.

18. Kaplan MH, Armstrong D, Rosen P. Tuberculosis complicating neoplastic disease. A review of 201 cases. Cancer 1974; 33: 850-58.

19. Leung WH, Tsang SF, Chim CS. Extrapulmonary tuberculous abscess in chronic lymphocytic leukaemia (CLL) treated with fludarabine: case report and review of literature. Am J Hematol 2005; 79: 246-47.

20. Bolton AE, Peng B, Hubert M. Effect of rifampicin on the pharmacokinetics of imatinib mesylate (Gleevec, STI571) in healthy subjects. Cancer Chemother Pharmacol 2004;53:102-6. 